\title{
Needle twins and right-angled twins in minerals: Comparison between experiment and theory
}

\section{Ekhard K.H. Salje, ${ }^{1, *}$ Andrew Buckley, ${ }^{1}$ Gustaaf Van Tendeloo, ${ }^{2}$ YoshiHIRo Ishibashi, ${ }^{3}$ and Gordon L. NORD Jr. ${ }^{4}$}

\author{
${ }^{1}$ Department of Earth Sciences, University of Cambridge, Downing Street, Cambridge CB2 3EQ, U.K. \\ ${ }^{2}$ EMAT, University of Antwerp-RUCA, Groenenborgerlaau 171, Antwerp, Belgium \\ ${ }^{3}$ Department of Applied Physics, School of Engineering, Nagoya University, Chikusa-ku, Nagoya 464-01, Japan \\ ${ }^{4} 956$ National Center, U.S. Geological Survey, Reston, Virginia 20192, U.S.A.
}

\begin{abstract}
Transformation twinning in minerals forms isolated twin walls, intersecting twin walls with corner junctions, and wedge-shaped twins as elements of hierarchical patterns. When cut perpendicular to the twin walls, the twins have characteristic shapes, right-angled and needle-shaped wall traces, which can be observed by transmission electron microscopy or by optical microscopy. Theoretical geometries of wall shapes recently derived for strainrelated systems should hold for most displacive and order-disorder type phase transitions: (1) right-angled twins show curved junctions; (2) needle-shaped twins contain flat wall segments near the needle tip if the elastic behavior of the mineral is dominated by its anisotropy; (3) additional bending forces and pinning effects lead to curved walls near the junction that make the needle tip appear more blunt. Experimental studies confirmed that these features occur in a wide range of materials. Bent right-angled twins were analyzed in $\mathrm{Gd}_{2}\left(\mathrm{MoO}_{4}\right)_{3}$. Linear needle tips were found in $\mathrm{WO}_{3},\left[\mathrm{~N}\left(\mathrm{CH}_{3}\right)_{4}\right]_{2} \cdot \mathrm{ZnBr}_{4} \mathrm{CrAl}, \mathrm{BiVO}_{4}$, $\mathrm{GdBa}_{2} \mathrm{Cu}_{3} \mathrm{O}_{7}$, and $\mathrm{PbZrO}_{3}$. Parabolic tips occur in $\mathrm{K}_{2} \mathrm{Ba}\left(\mathrm{NO}_{2}\right)_{4}$, and GeTe whereas exponential curvatures appear in $\mathrm{BaTiO}_{3}, \mathrm{KSCN}, \mathrm{Pb}_{3}\left(\mathrm{PO}_{4}\right)_{2}, \mathrm{CaTiO}_{3}$, alkali feldspars, $\mathrm{YBa}_{2} \mathrm{Cu}_{3} \mathrm{O}_{7}$, and $\mathrm{MnAl}$. The size and shape of the twin microstructure relates to its formation during the phase transition and the subsequent annealing history. The mobility of the twin walls after formation depends not only on the thermal activation but also on the structure of the wall, which may be pinned to impurities on a favorable structural site. Depinning energies are often large compared with thermal energies for diffusion. This leads to kinetic time scales for twin coarsening that are comparable to geological time scales. Therefore, transformation twins that exhibit needle domains not only indicate that the mineral underwent a structural phase transition but also contain information about its subsequent geological history.
\end{abstract}

\section{INTRODUCTION}

Atomic ordering in minerals can be slow enough that thermodynamic equilibrium is not always achieved on a geological time scale. A typical example is $\mathrm{Al}$ and $\mathrm{Si}$ ordering in feldspars. Such ordering occurs in anorthite on a laboratory time scale at temperatures above $1100 \mathrm{~K}$, in geological samples at temperatures above $700 \mathrm{~K}$ and virtually never at lower temperatures (Smith 1974a; Salje et al. 1993; Wruck et al. 1991; Salje et al. 1985). Experimental observation of incomplete order in minerals and the theoretical analysis of its time dependence can be forged into a powerful tool for the unraveling of geological processes.

In contrast to atomic ordering processes, purely displacive phase transitions are seemingly less useful for the analysis of kinetic processes. The conjecture could be that

\footnotetext{
*E-mail: es10002@esc.cam.ac.uk
}

displacive processes are not thermally activated and occur on a (fast) phonon time scale and, thus, do not lead to non-equilibrium features that could survive the thermal history of geological processes. This conjecture is wrong, however, as can be seen by the following example.

A ferroelastic phase transition will, in most cases, produce twinning in the low-symmetry phase whereas no such twinning exists in the high-symmetry phase (Burger 1945; Xu and Heaney 1997; Xu et al. 1997). The nature of the phase transition (e.g., atomic ordering or displacive transitions) is irrelevant for the generation of twinning. A twin wall represents an excited state of the mineral, i.e., the twin wall increases the total energy of a crystal (Salje 1993b; Houchmanzadeh et al. 1991; Tsatskis and Salje 1996). There is no mechanism in a stress-free crystal by which the crystal could get rid of the twin wall. The only geometrical solution is the lateral movement of the wall until it disappears through the surface. This lateral move- 

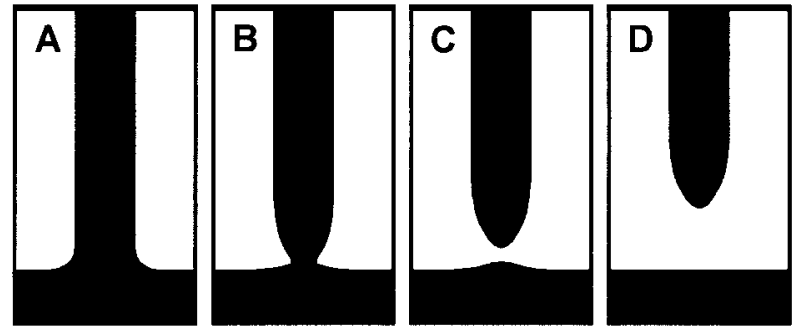

Figure 1. Formation of needle twin via the attraction of two right-angled twin walls (A). The two corners approach each other (B) and merge (C). The needle twins is formed with parallel walls at the shaft. These walls are perpendicular to the horizontal twin wall in $\mathbf{D}$.

ment is prevented by lattice pinning and the fact that atomic fluctuations around the twin wall will not lead to its macroscopic movement even on a geological time scale. These arguments show that unstable or weakly metastable twin walls have no kinetic decay mechanism and, thus, will not disappear in a stress free mineral (Tsatskis et al. 1994; Salje 1993b). This is the reason for the common preservation of twin walls and similar domain structures in minerals, even of great geological age. These similar domain structures include antiphase domains and exsolution as well as twins (e.g., Wyart 1938; Peacor 1968; Sadanaga and Ozawa 1968; Mazzi et al. 1976; Heaney and Veblen 1990; Gordon et al. 1981; Carpenter 1994; Müller and Wenk 1973; Heuer et al. 1976; Smith and Brown 1988; Van Tendeloo et al. 1976)

The curious situation is that displacive ferroelastic phase transitions occur on a very fast (phonon) time scale, whereas their hallmark is the twin walls that exist virtually forever. Nevertheless the fine-scale structures of the wall may evolve on an intermediate, geological time scale. This evolution is related to the fact that twin walls can generate hierarchical structures, such as wedgeshaped twins (needle twins) and twins with right-angles (corner twins). Such microstructures have obvious decay paths. A needle twin can simply be destroyed by pulling the needle tip back. This allows the adjacent twins to coarsen. Corner twins, on the other hand, can combine to form needles (Salje 1993a, 1993b). This latter process is of fundamental importance for the formation of needle twins, because it also represents the first dynamical step in the kinetics of pattern formation in ferroelastic minerals. The time sequence is shown schematically in Figure 1. Two corner twins walls with opposite curvature (A), attract each other (B) whereby the attractive force depends logarithmically on the distance between the corners. Once the two corners merge (C) the two twins coalesce (D). The final configuration is then a straight twin wall and a needle twin that is aligned perpendicular to the twin wall. The further kinetic history of this configuration is now determined by the retraction of the needle twins and the further coalescence of the two adjacent twins (Fig. 2). The rate of retraction is determined by the pinning of the twin walls of the needle, in particular the pinning of the needle tip. Roughly speaking, minerals that were heated for long periods of time at sufficiently high temperatures should show no needle twins whereas low temperature anneals should maintain needle twins.

Needle twins have not been systematically sought in geological samples but are evident in feldspars, perovskites, leucites, baddeleyite, tridymite, cordierite, palmierite, for example (Hayward et al. 1996; Smith et al. 1987; Hu et al. 1992; Wang and Lieberman 1993; Palmer et al. 1988; Müller and Schreyer 1991; Bismayer and Salje 1981; Putnis and Salje 1994). Before such needle twins can be used as indicators for the thermal history of a sample, a much better understanding of their energetics is required. Salje and Ishibashi (1996) showed that the detailed needle structure reflects some of the most fundamental characteristics of twin walls themselves. These ideas are developed further in this paper. The characteristic shapes of needle domains are described and compared with experimental results.

\section{THE THICKNESS OF TWIN WALLS AND THEIR BENDING}

Experimental investigations of the thickness of twin walls, i.e., the boundary layer between two adjacent twin individuals, have shown thicknesses between some 0.7 $\mathrm{nm}$ and $6 \mathrm{~nm}$. The displacive phase transition $C 2 / m-C \overline{1}$ in hypersolvus alkali feldspars is a typical example for twin walls of moderate thickness (Hayward and Salje 1996). This phase transition generates so-called albitetwin walls and pericline-twin walls. The latter walls were analyzed in detail and a thickness of $2.5 \mathrm{~nm}$ was found at low temperatures; at higher temperatures this wall thickness increases as the transition temperature is approached.

The temperature dependence of the thickness $w$ confirms approximately the predictions of classic Landau Ginzburg theory (e.g., Salje 1993b for a review). For a ferroelastic mineral, the energy density $(G)$ for the most simple case of a non-degenerate order parameter $(Q)$ and a quadratic Ginzburg energy (with the energy coefficient $g$ ) is

$$
G=\frac{1}{2} \mathrm{~A}\left(T-T_{\mathrm{c}}\right) Q^{2}+\frac{1}{4} \mathrm{~B} Q^{4}+\frac{1}{2} g(\nabla Q)^{2}
$$

where A and B are constants, $T$ is temperature and $T_{\mathrm{c}}$ is the transition temperature. Here we consider the most simple case where the spontaneous strain is proportional to the order parameter $Q$.

The profile of a twin wall follows from the condition that the total strain energy of the wall is minimal.

$$
\int G(Q, \nabla Q) \mathrm{d} y=\text { minimum }
$$

and where $y$ is the coordinate perpendicular to the twin wall. The minimum condition is given by the Euler-Lagrange equation for $G$ for $T<T_{\mathrm{c}}$ : 

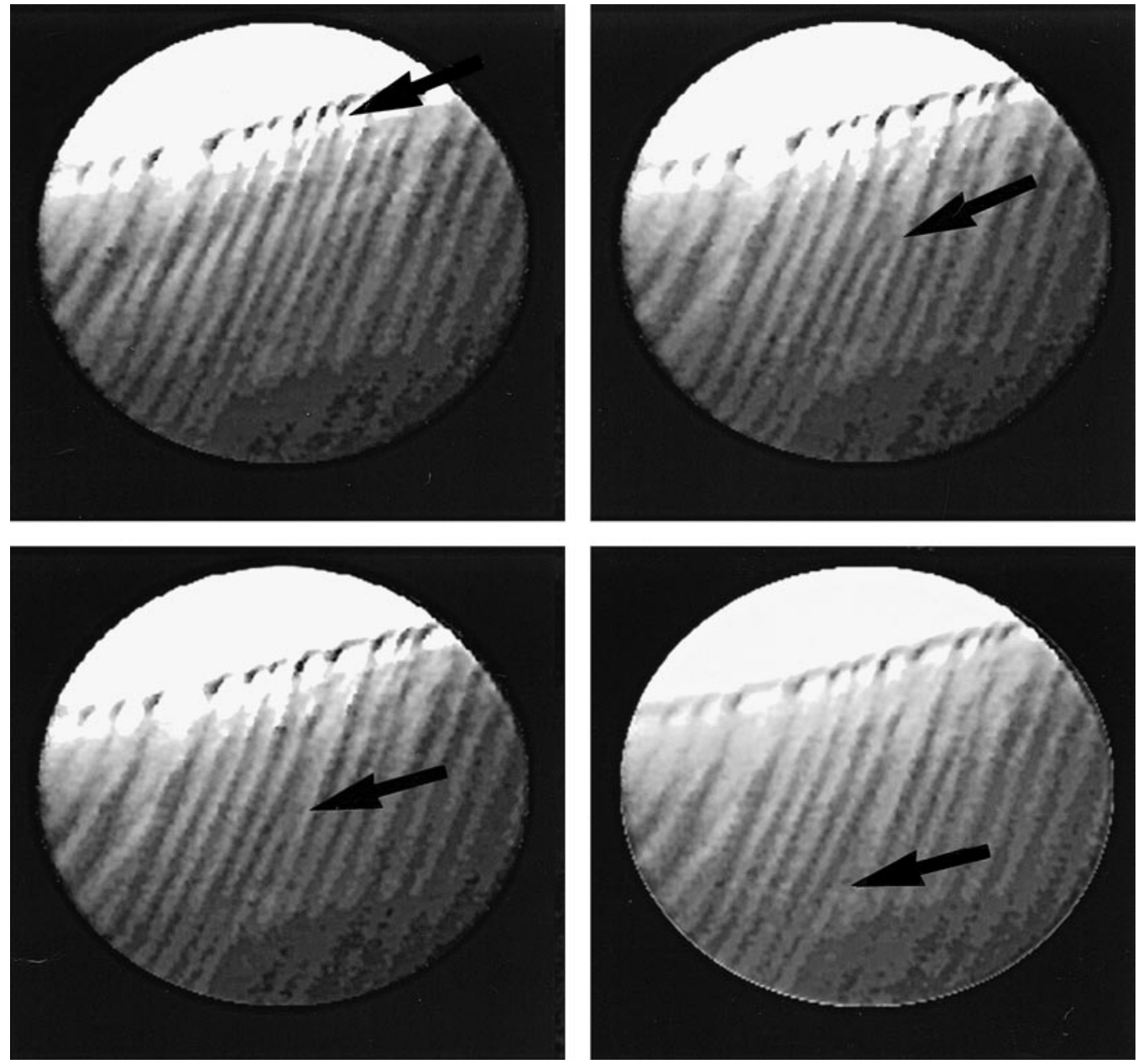

Figure 2. Retraction of a needle twin in $\mathrm{YBa}_{2} \mathrm{Cu}_{3} \mathrm{O}_{7-\delta}$. A comb configuration of needle twins (top left) contains close to the center of the image a slightly twisted needle. This needle unpins and retracts. The new tip positions are indicated by arrows.

$$
g \frac{\mathrm{d}^{2} Q}{\mathrm{~d} y^{2}}=\mathrm{A}\left(T-T_{\mathrm{c}}\right) Q+\mathrm{B} Q^{3}
$$

with the solution of the strain profile across a twin wall

$$
Q \propto e=e_{0} \tanh \frac{y}{w}
$$

where $e$ is the relevant component of the spontaneous strain, $e_{0}$, is the spontaneous strain inside the twin, and $y$ is the space coordinate perpendicular to the wall. The parameter $w$ is

$$
w^{2}=\frac{2 g}{\mathrm{~A}\left(T_{\mathrm{c}}-T\right)}=w_{0}^{2}\left(\frac{T_{\mathrm{c}}}{T_{\mathrm{c}}-T}\right) .
$$

In proper ferroelastic phase transitions $\mathrm{A}\left(T-T_{\mathrm{c}}\right)$ is an appropriate elastic constant in the paraelastic phase, in other cases this parameter is a more complex function related to the excess entropy of the phase transition. For anorthoclase, Hayward et al. (1996) and Hayward and Salje (1996) found $\mathrm{A}=8.2 \mathrm{~J} /(\mathrm{mol} \cdot \mathrm{K})$ and $2 w_{0}=2.5 \mathrm{~nm}$, which leads to a Ginzburg parameter $g=4 \times 10^{-15} \mathrm{Jm}^{2} /$ mol. This value is similar to $g=5 \times 10^{-15} \mathrm{Jm}^{2} / \mathrm{mol}$ for twin walls in $\mathrm{YBa}_{2} \mathrm{Cu}_{3} \mathrm{O}_{7}$ (Chrosch and Salje 1994).

The bending of twin walls is the essential ingredient for the formation of needle twins. Three energy contributions for the bending of twin walls were identified by Salje and Ishibashi (1996). The first contribution is the elastic "anisotropy energy," which is the energy required for the rotation of a twin wall. The rotation axis lies inside the wall. Such rotation would lead to the formation of dislocations if the released energy becomes comparable with the dislocation energy. In displacive phase transitions, such dislocations have not been observed experimentally so the energy must be dissipated without topological defects. In this case, the energy density is for small rotation angles $\alpha=2 \mathrm{~d} y / \mathrm{d} x$ :

$$
E_{\text {anisotropy }}=\mathrm{U}\left(\frac{\mathrm{d} y}{\mathrm{~d} x}\right)^{2}
$$

where the $y$ axis is again perpendicular to the unperturbed wall, the $x$ axis is parallel to the unperturbed wall segment 


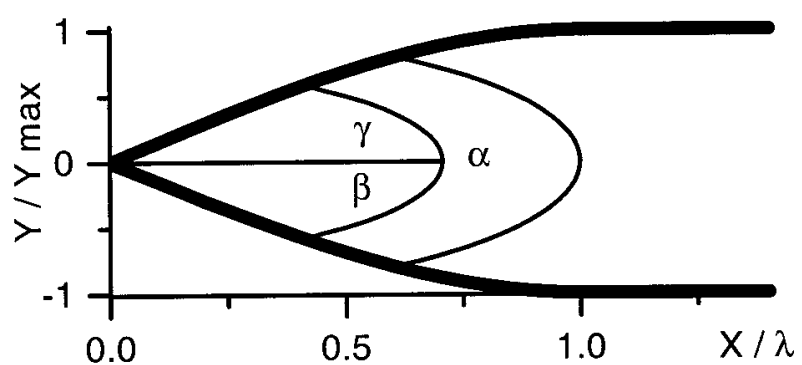

Figure 3. Wall profile as calculated for needles with large curvature energy and no lattice relaxation (see Salje and Ishibashi 1996). Coordinate system used in text shown. For single needles $\gamma=\beta=\alpha / 2$, for forked needles observed $\beta \leq \gamma$ where $\beta$ is interior angle of forked pair.

(i.e., without the rotation), and $\mathrm{U}$ is a constant derived by Salje and Ishibashi (1996).

The second energy contribution stems from the fact that a wall with a finite thickness will resist bending because bending implies compression of the wall on one side and extension on the other. The energy density of this "bending energy" is

$$
E_{\text {bending }}=\mathrm{S}\left(\frac{\mathrm{d}^{2} y}{\mathrm{~d} x^{2}}\right)^{2}
$$

where $\mathrm{S}$ is a constant defined by Salje and Ishibashi (1996).

Finally, lateral movement of the wall is resisted by pinning as described by the "Peierls energy":

$$
E_{\text {pinning }}=\mathrm{P} y^{2}
$$

which holds for small values of $y$. The parameter $P$ is a measure for the Peierls energy, more complex Peierls energies were discussed by Salje and Ishibashi (1996).

The shape of a needle twins, i.e. the trajectory of the wall position $y(x)$, is determined by the minimum of the total energy

$$
\delta E=\delta \int\left(E_{\text {anisotropy }}+E_{\text {bending }}+E_{\text {pinning }}\right) \mathrm{d} x=0 .
$$

The following solutions were found by Salje and Ishibashi (1996), the coordination system is shown in Figure 3 . For case 1, bending dominated needles without lattice relaxation, the wall trajectory is close to a parabolic shape

$$
y=\frac{y_{\max }}{2 \lambda^{3}}(\lambda-x)^{2}(2 \lambda+x)
$$

where $y_{\max }$ is the position of the needle tip and $\lambda$ is the distance (along the $x$ axis) between the needle tip and the shaft of the needle. This trajectory contains no adjustable parameters and has no characteristic length scale. Needles of this type are, thus, universal, i.e., their shape does not depend on temperature, pressure, or the actual mineral in which they occur. For case 2, anisotropy dominated needles without lattice relaxation, the trajectory is linear with

$$
y=y_{\max }(1-x / \lambda) \text {. }
$$

This trajectory is also universal. For case 3, anisotropy dominated needles with elastic lattice relaxation or superposition of anisotropy energy and bending energy, we expect an exponential trajectory

$$
y=y_{\max } \exp (-x / \lambda) .
$$

The value of $\lambda$ depends on the lattice relaxation $\lambda^{2}=U / P$, which is no longer a simple geometrical parameter. In particular, the ratio U/P may depend on temperature and pressure so that small Peierls energies will favor long, pointed needles whereas large Peierls energies lead to short needles. In the case of superposition of anisotropy and bending energies the length scale is set by $\lambda^{2}=\mathrm{S} / \mathrm{U}$, which is also a non-universal parameter.

A large variety of other functional forms of the wall trajectories were discussed by Salje and Ishibashi (1996). Only the above three cases are used to discuss the experimental observations in this paper.

The trajectory of a corner wall (See Fig. 1) in the limit of large anisotropy energies and bending energies is approximated by Salje and Ishibashi (1996)

$$
y=\lambda \ln \left[\cosh \frac{x}{\lambda}\right], \quad \lambda^{2}=\mathrm{S} / \mathrm{U} .
$$

The parameter $\lambda$ is not universal and may depend on temperature and pressure.

\section{EXPERIMENTAL TECHNIQUES}

The digital images of needle twins used for this work were either produced by scanning photographs from published material, at a resolution of 1200 dpi or using a microscope and CCD camera system to capture images of samples in our lab. Needles with tip angles of much less than $1.5^{\circ}$ cannot be handled by the imaging equipment and software combination used. Both TEM and optical images of needles were collected so the widths range from $40 \mu \mathrm{m}$ down to $9 \mathrm{~nm}$.

The software used in the fitting process allowed the images to be freely stretched or contracted along one or the other orthogonal axis by more than a factor of 10 . Applying such distortions made mismatches much more clearly visible, greatly facilitating the refinement of fit parameters.

Because of constraints imposed by the imaging and scanning equipment, some preliminary fitting procedures were made before refining the fit of the relevant functions. The exact position of the termination of the needle tip must be known to define the origin; even though many of the images do not include the needle tip termination (due to termination against other twin walls or the edge of the crystal) symmetry requirements allow the needle center line to be determined and hence the offset in $y$. Initially the $x$ offset can be approximated as errors as this will only cause a translation in the fitted function without affecting the overall shape. This translation can subsequently be corrected to produce a match between the function and the needle.

Preparing the images so that the twin center lines are 

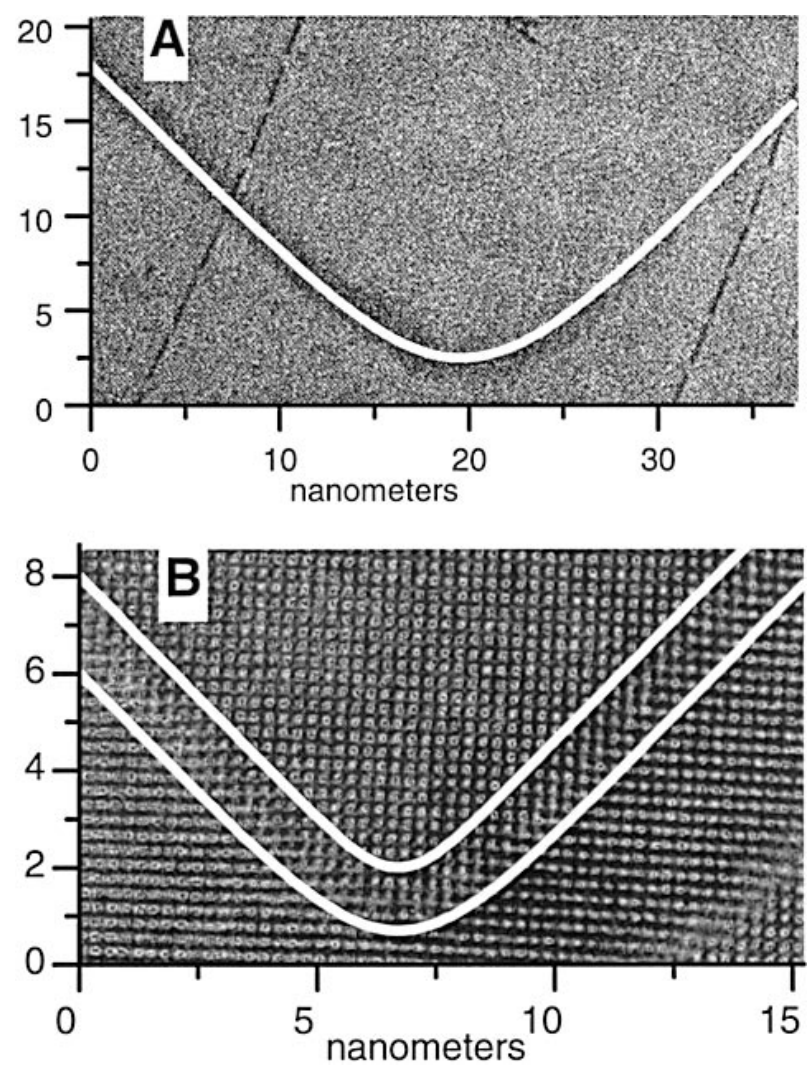

Figure 4. Images of right angle twin walls and the fitted wall trajectories. (A) $\mathrm{Gd}_{2}\left(\mathrm{MoO}_{4}\right)_{3}$, (B) $\mathrm{YBa}_{2} \mathrm{Cu}_{3} \mathrm{O}_{7-\delta \text {. }}$ (cf. Fig 1a). Both axes have the same units.

exactly parallel to the fitting axes is virtually impossible. In some cases a deviation of up to $5^{\circ}$ occurred. Rotation of the images by software was avoided because the corrections applied by the imaging software to maintain pixel shape were not sufficiently well known. Furthermore, as it is necessary to determine a straight line fit to the edges and center line of the needle to calculate the origin and the rotation angle, this deviation was incorporated into the function fit. If these three lines were not parallel, or the edges were not symmetrical about the center line intersecting the needle tip, then that image was discarded. When two or more adjacent twins were fitted they should have parallel center lines. The refined parabolic function requires the length of the needle tip to be determined. To achieve the greatest accuracy, the area where the needle tip meets the shaft should be clear on the original image and the needle tip termination must be identified. Obviously needles that are too short to extend as far as the shaft cannot be fitted as accurately so these were generally avoided.

In addition to needles that do not have a symmetrical width about the center line, those that do not have a symmetrical curvature are also discarded. Closer examination of needles that did not satisfy these criteria invariably
TABLE 1. Fitting parameter $(\lambda)$ for right angle twin walls

\begin{tabular}{llr}
\hline \hline Material & \multicolumn{1}{c}{ Reference } & $\lambda$ \\
\hline $\mathrm{Gd}_{2}\left(\mathrm{MoO}_{4}\right)_{3}$ & Yamamoto et al. 1977 & 6 \\
$\mathrm{YBa}_{2} \mathrm{Cu}_{3} \mathrm{O}_{7}$ & Zhu et al. 1993 & inner: 1 \\
& & outer: 2 \\
\hline
\end{tabular}

revealed signs of lattice distortions in the region caused by defects or needle terminations against defects.

\section{COMPARISON WITH EXPERIMENTAL OBSERVATIONS Right-angled twin walls}

TEM images of right-angle twin walls were available for two materials, $\mathrm{Gd}_{2}\left(\mathrm{MoO}_{4}\right)_{3}$ and $\mathrm{YBa}_{2} \mathrm{Cu}_{3} \mathrm{O}_{7}$. The fitted trajectories are in Figure 4 and specific details are in Table 1. The $\mathrm{YBa}_{2} \mathrm{Cu}_{3} \mathrm{O}_{7}$ sample has the smaller bending radius of the inner rim of the thick boundary. This image was taken at a higher resolution and the curvature of the outer and inner contacts of the twin walls were modeled separately using Equation 13.

\section{Temperature evolution of needle twins}

To investigate the dependence of needle behavior on formation conditions, images of the needles developing in a sample of $\mathrm{Pb}_{3}\left(\mathrm{PO}_{4}\right)_{2}$ were captured at $1 \mathrm{~K}$ intervals as this material was heated through $T_{\mathrm{c}}$. Two sets of nine images were collected as the sample was heated toward $T_{\mathrm{c}}$ and a further two sets as the sample was cooled from $T_{\mathrm{c}}$. These images were fit with an exponential function. In all cases, the needles formed within $2 \mu \mathrm{m}$ of the preheating location each time the sample was cooled through the phase transition temperature. The shape of the needle twins did not change with temperature.

\section{Linear needle tips}

Needle twins with linear trajectories close to the needle tip were found in a several ferroelastic materials such as $\mathrm{PbZrO}_{3}, \mathrm{WO}_{3}, \mathrm{BiVO}_{4}, \mathrm{GdBa}_{2} \mathrm{Cu}_{3} \mathrm{O}_{7},\left[\mathrm{~N}\left(\mathrm{CH}_{3}\right)_{4}\right]_{2} \cdot \mathrm{ZnBr}_{4}$, and the alloy CrAl. Fit parameters are in Table 2. Typical examples are shown in Figure 5.

In all of these materials, the change between the shaft of the needle and the tip is abrupt. The straight trajectory at the needle tip indicates that the anisotropy energy of these crystals is much larger than the bending energy and that Peierls energies are unimportant (besides for the pinning of the shaft).

The three needles measured from the same specimen of $\mathrm{CrAl}$ each have the same needle tip angle, two of these terminate against the same $90^{\circ}$ twin wall. Although there is a general relationship between the angle at the needle tip and the needle width, for a particular sample, such as $\mathrm{CrAl}$, it appears that the tip angle is uniform and the variation in needle width is accommodated more by a corresponding increase in $\lambda$. This is in contrast to the parabolic and exponential cases in which the angle at the tip varies systematically with the width of the twin. 
TABLE 2. Materials having linear needle trajectories

\begin{tabular}{|c|c|c|c|c|}
\hline Material & Reference & Length $(\lambda)$ & Tip-angle & $y_{\max }$ \\
\hline $\mathrm{WO}_{3}$ & Microanalysis Lab, Cambridge & $680 \mu \mathrm{m}$ & 1.6 & $9 \mu \mathrm{m}$ \\
\hline$\left[\mathrm{N}\left(\mathrm{CH}_{3}\right)_{4}\right]_{2} \cdot \mathrm{ZnBr}{ }_{4}$ & Sawada (personal communication) & no scale & 4 & 12 \\
\hline CrAl & Van Tendeloo (personal communication) & $300 \mathrm{~nm}$ & 6.8 & $18 \mathrm{~nm}$ \\
\hline CrAl & Van Tendeloo (personal communication) & $367 \mathrm{~nm}$ & 6.8 & $22 \mathrm{~nm}$ \\
\hline CrAl & Van Tendeloo (personal communication) & $375 \mathrm{~nm}$ & 6.8 & $22 \mathrm{~nm}$ \\
\hline${ }^{*} \mathrm{BiVO}_{4}$ & Van Tendeloo (spout) & $320 \mathrm{~nm}$ & 8.9 & $25 \mathrm{~nm}$ \\
\hline $\mathrm{GdBa}_{2} \mathrm{Cu}_{3} \mathrm{O}_{7}$ & Shmytko et al. 1989 & no scale & 10.3 & 2 \\
\hline${ }^{*} \mathrm{PbZrO}_{3}$ & Dobrikov and Presnyakova 1980 & $300 \mathrm{~nm}$ & 12.5 & $33 \mathrm{~nm}$ \\
\hline
\end{tabular}

Note: Fitting parameters are $y_{\max }$ and tip angle. $\lambda$ calculated from these.

* Illustrated in Figure 5.

\section{Curved trajectories}

Bending dominated wall energies are predicted to lead to trajectories of a modified parabolic shape. Such needles have been observed in the alloy GeTe and in $\mathrm{K}_{2} \mathrm{Ba}\left(\mathrm{NO}_{2}\right)_{4}$ (Fig. 6). Table 3 summarizes the fit parameters.

Needle twin walls with exponential trajectories were observed in many ferroelastic materials such as $\mathrm{Pb}_{3}\left(\mathrm{PO}_{4}\right)_{2}$ (Fig. 7), and KSCN (Fig. 8) and for twin walls in $\mathrm{BaTiO}_{3}$ (Fig. 8). Typical length scales $\lambda$ are $85 \mu \mathrm{m}$ (KSCN), 55 $\mathrm{nm}$ to $3 \mu \mathrm{m}\left[\mathrm{Pb}_{3}\left(\mathrm{PO}_{4}\right)_{2}\right]$ and $270 \mathrm{~nm}\left(\mathrm{BaTiO}_{3}\right)$, see Table 4. Furthermore, although the parabolic and linear cases show a correlation between the tip angle and needle width this is less apparent for the exponential needles. The tip angle for these materials is considerably greater than for parabolic materials of similar width (Fig. 9).

\section{Needle splitting}

In several materials needles were observed that had formed a 'tuning fork' pair rather than a single needle.
Examples of this were observed in $\mathrm{GdBa}_{2} \mathrm{Cu}_{3} \mathrm{O}_{7}$, $\mathrm{YBa}_{2} \mathrm{Cu}_{3} \mathrm{O}_{7}, \mathrm{~Pb}_{3}\left(\mathrm{PO}_{4}\right)_{2}$ (Fig. 10) and $\mathrm{BaTiO}_{3}$ (Table 5). Kfeldspar (Smith et al. 1987) and $\mathrm{La}_{2-x} \mathrm{Sr}_{x} \mathrm{CuO}_{4}$ (Chen et al. 1991) also show twins of this type but these could not be analyzed quantitatively. In all of these cases the two halves of the split needle were the same but each half was asymmetric; the needle tips being displaced towards the center line of the pair. $\mathrm{GdBa}_{2} \mathrm{Cu}_{3} \mathrm{O}_{7}$ had linear needle tip trajectories (as was found for the simple needles of this material) and the inner and outer tip angles were the same. The other materials measured had exponential needle tips and the inner tip angle was less than the outer. Single needles of comparable width were measured from the same samples as each of the four split needles examined in detail so a direct comparison can be made between these. The split needle twins were always the widest in the sample, and there appears to be a limiting tip angle for a particular material above which splitting occurs to produce a joined pair of needles with a much reduced tip angle.
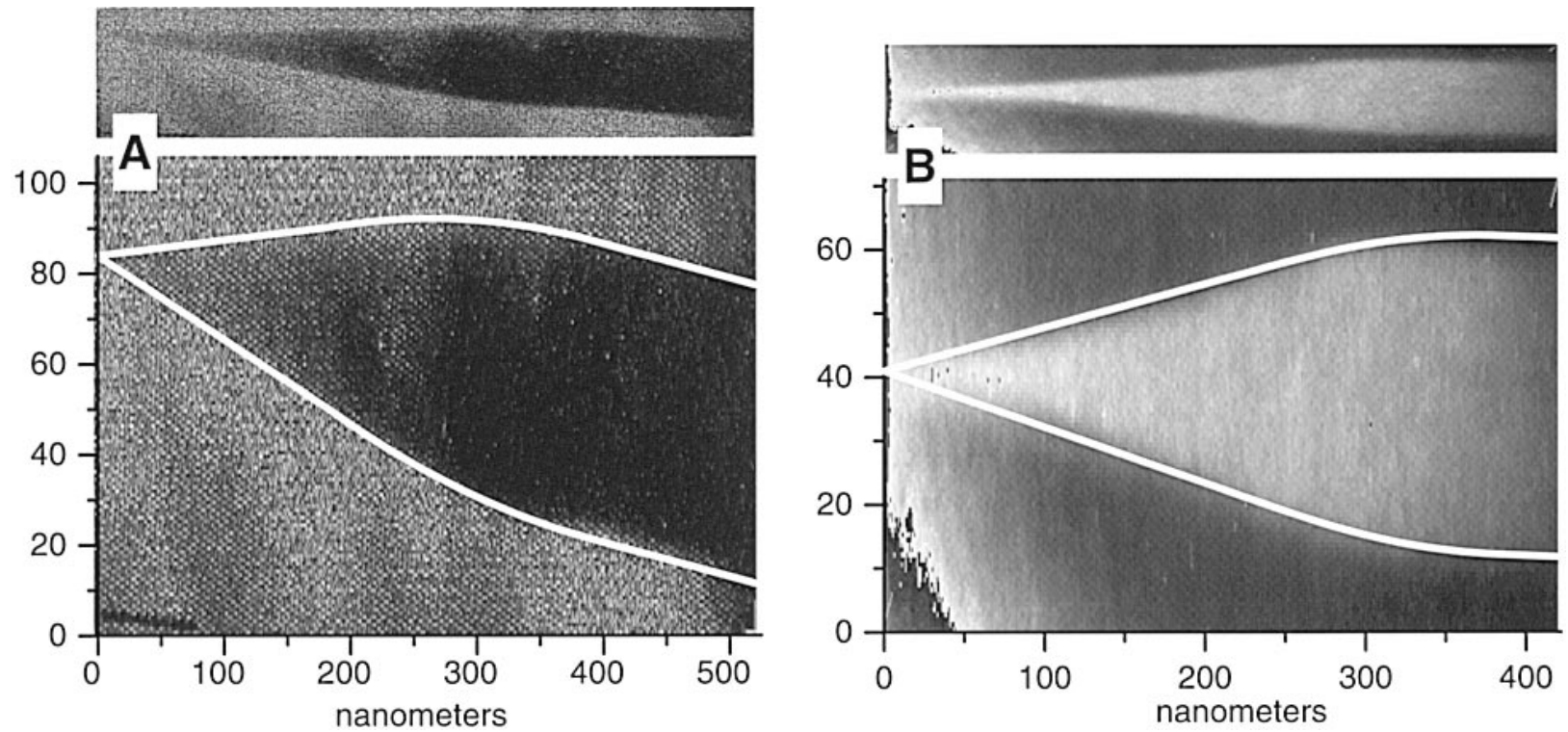

Figure 5. Images of linear needle tips. The lines drawn are straight line fits along the shaft and tip, the two lines being joined with a parabola. The upper images show the true aspect ratio, the lower images show the $y$ axis expanded to demonstrate the linear nature of the needle tip. The apparent asymmetry in the latter is due to the non-linear expansion. Left: $\mathrm{PbZrO}_{3}$, right: $\mathrm{BiVO}_{4}$. $\mathrm{Both}$ axes have the same units. 

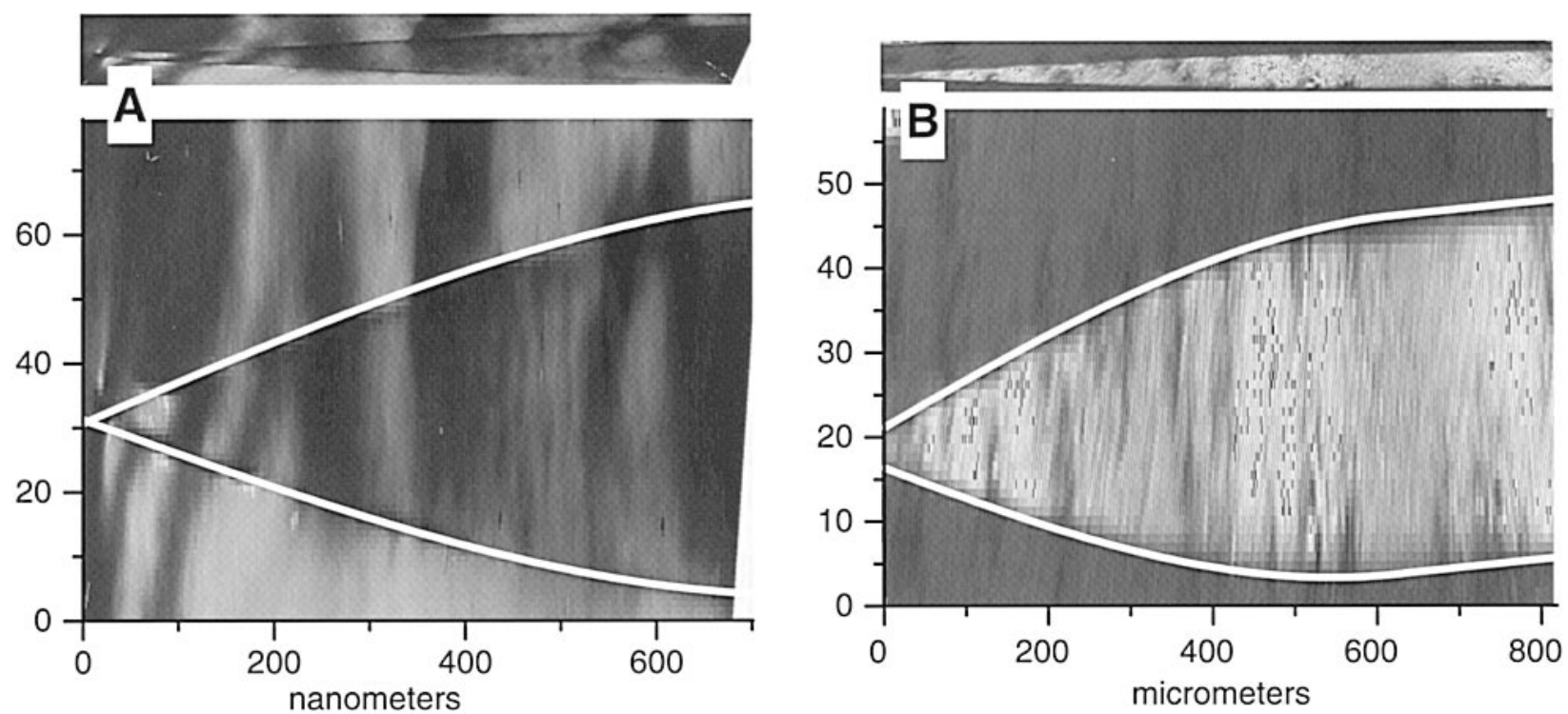

Figure 6. Needle twins, with curved trajectories. The upper images show the true aspect ratio, the lower images show the $y$ axis expanded to demonstrate the curvature of the needle tip. In both cases the tip of the needle is truncated against another feature so the needle origin must be estimated, from the position of the center line, to determine $\lambda$. (A) GeTe, $(\mathbf{B}) \mathrm{K}_{2} \mathrm{Ba}\left(\mathrm{NO}_{2}\right)_{4}$. Both axes have the same units.

If a needle with a large tip angle is to split into a pair of needles with smaller tip angles the sum of these energies plus the energy of the tip must be less than that of the single, blunter needle. Estimates of the energy contribution due to the anisotropy energy of the needles were made for the split needle as observed (case a), a single needle of the same width and tip angle as the split needle (case b), a single needle of the same width and tip length $(\lambda)$ as the split needle (case c). As a measure for the energy (Eq. 6) the square of the angle $\frac{\alpha}{2}$ was multiplied with the length of the needle tip (i.e., the rotated part of the twin wall) for each configuration of a, b, and c. From Table 5, the energy in case $\mathrm{c}$ is always the greatest with the single needle energy in case $b$ slightly higher than the split energy in case a.

\section{Discussion}

The experimental observations confirm the predicted trajectories of needle twin walls. The most obvious distinction is between materials with linear trajectories $\left\{\mathrm{WO}_{3},\left[\mathrm{~N}\left(\mathrm{CH}_{3}\right)_{4}\right]_{2} \cdot \mathrm{ZnBr}_{4}, \mathrm{CrAl}, \mathrm{BiVO}_{4}, \mathrm{GdBa}_{2} \mathrm{Cu}_{3} \mathrm{O}_{7}\right.$, $\left.\mathrm{PbZrO}_{3}\right\}$ and those with curved needle tips. Among ma- terials with curved trajectories, the difference between "parabolic" and "exponential" shapes is subtle, in both cases no abrupt change between the shaft of the needle and the needle tip occurs. The shape of the needle tips are characteristic for a material and seem not to change with temperature or thermal history of the sample. Local variations of trajectories are due to defects and external stress fields although undisturbed needles were easily found in most samples.

The experimental observations also indicate some limitations for the thickness of needles and tip angles. Two parallel twin walls may form a needle twin via the attraction of corner junctions if the original distance $(r)$ between the corners is smaller than an "unbinding distance" $R_{0}$. The attractive force between the corner for a distance $r<R_{0}$ is $F \propto \ln r / R_{\mathrm{o}}$ (Salje 1993a). The numerical value of $R_{0}$ depends on the geometrical configuration of the corners, e.g., the sample size, the influence of surface relaxations, and that of other interacting domain structures. In this study, needle twins with a thickness of the shaft of some $40 \mu \mathrm{m}\left[\mathrm{K}_{2} \mathrm{Ba}\left(\mathrm{NO}_{2}\right)_{4}\right]$ or $24 \mu \mathrm{m}(\mathrm{KSCN})$ have been observed. No wall bending that could be re-

TABLE 3. Materials having modified parabolic needle tip trajectories

\begin{tabular}{|c|c|c|c|c|}
\hline Material & Reference & Length $(\lambda)$ & Tip-angle & $y_{\max }$ \\
\hline $\mathrm{K}_{2} \mathrm{Ba}\left(\mathrm{NO}_{2}\right)_{4}$ & Microanalysis Lab, Cambridge & $600 \mu \mathrm{m}$ & 4.5 & $16 \mu \mathrm{m}$ \\
\hline${ }^{*} \mathrm{~K}_{2} \mathrm{Ba}\left(\mathrm{NO}_{2}\right)_{4}$ & Microanalysis Lab, Cambridge & $670 \mu \mathrm{m}$ & 5.5 & $21 \mu \mathrm{m}$ \\
\hline GeTe & Van Tendeloo (pers. comm) & $750 \mathrm{~nm}$ & 8.0 & $35 \mathrm{~nm}$ \\
\hline${ }^{*} \mathrm{GeTe}$ & Van Tendeloo (pers. comm) & $790 \mathrm{~nm}$ & 6.7 & $31 \mathrm{~nm}$ \\
\hline GeTe & Van Tendeloo (pers. comm) & $820 \mathrm{~nm}$ & 10.2 & $49 \mathrm{~nm}$ \\
\hline
\end{tabular}

Note: Fitting parameters are $\lambda$ and $y_{\max }$. Tip angle calculated from these.

* Illustrated in Figure 6. 

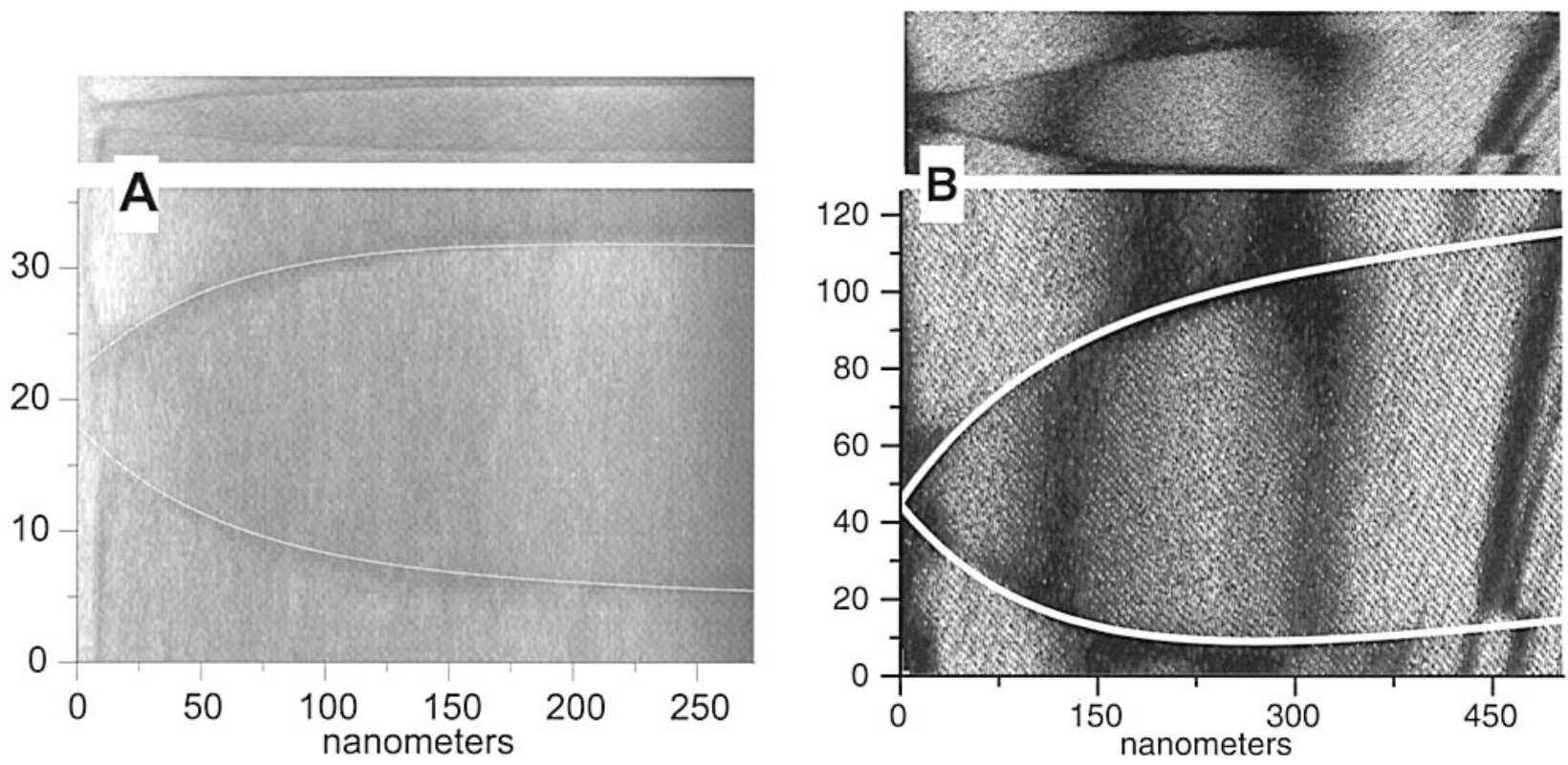

Figure 7. Needle twins with exponential trajectories. The upper images show the true aspect ratio, the lower images show the $y$ axis expanded to demonstrate the curvature of the needle tip. In both cases the tip of the needle is truncated against another domain wall so the needle origin must be estimated, from the position of the center line, to determine $\lambda$. Both images: $\mathrm{Pb}_{3}\left(\mathrm{PO}_{4}\right)_{2}$. (cf. Fig. 1B). Both axes have the same units.

lated to the attraction of two corners was found in the $\mathrm{Pb}_{3}\left(\mathrm{PO}_{4}\right)_{2}$ crystals for corner distances larger than $80 \mu \mathrm{m}$. This indicates that the elastic attractive force is screened over this distance by other relaxational mechanisms. The effective forces on the two corners are then weak compared with local pinning forces and no wall bending occurs. The typical needle thicknesses range from $9 \mathrm{~nm}$ to $20 \mu \mathrm{m}$. Very few, heavily forked needles with larger thickness were found. Zigzag walls are extreme cases of multiple fork needles.

No needle twins with a thickness less than $9 \mathrm{~nm}$ have been observed in any of our samples. It is expected that parallel walls with smaller distances easily break up by necking and annihilate the thin walls between the two walls. (Salje 1993b). Remnants of fragmented thin twins form lens-shapes not unlike those found in exsolution mi-
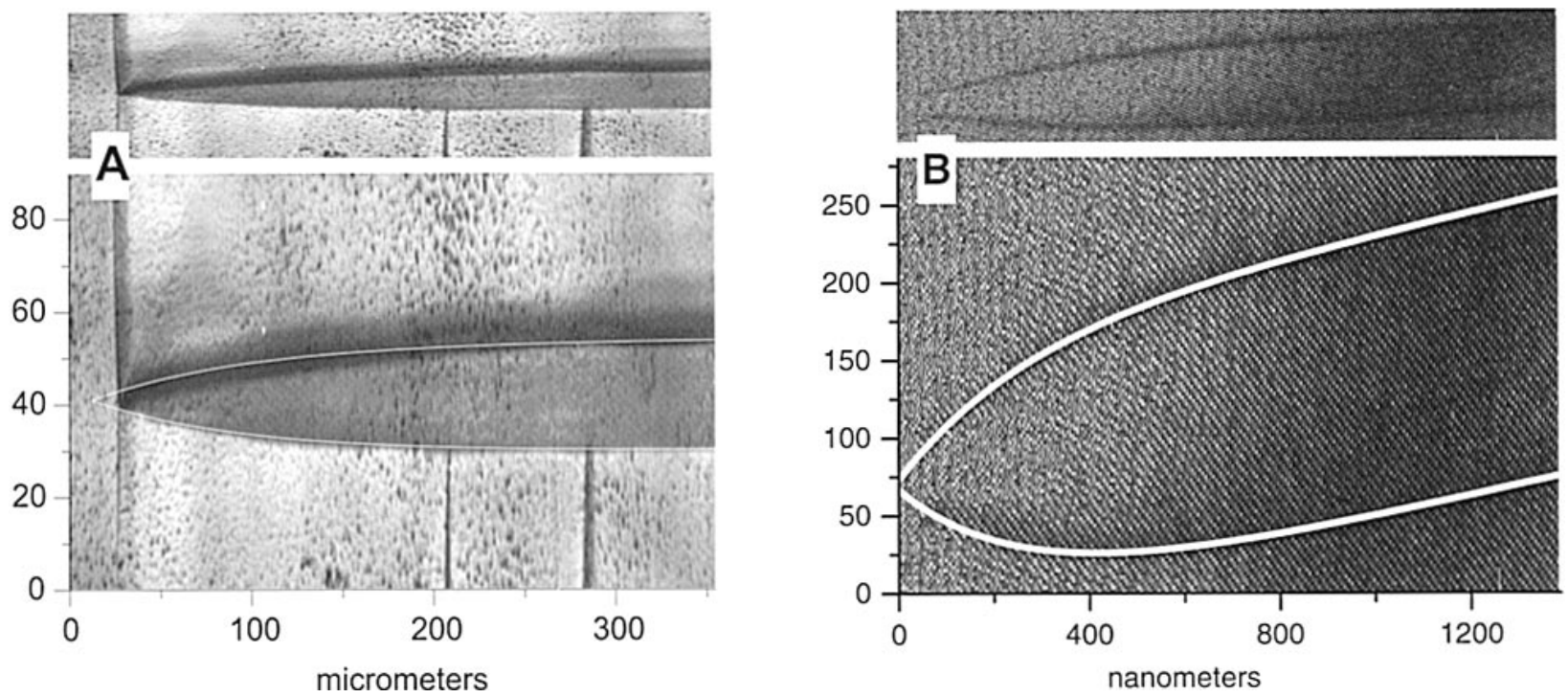

Figure 8. Needle twins in $\mathrm{KSCN}(\mathbf{A})$ and $\mathrm{BaTiO}_{3}(\mathbf{B})$. The trajectories were fit with an exponential function. The upper images show the true aspect ratio, the lower images show the $y$ axis expanded to demonstrate the curvature of the needle tip. The apparent asymmetry in the latter is due to the non-linear expansion. Both axes have the same units. 
TABLE 4. Materials having exponential needle tip trajectories

\begin{tabular}{|c|c|c|c|c|}
\hline Material & Reference & Length $(\lambda)$ & Tip-angle & $y_{\max }$ \\
\hline${ }^{*} \mathrm{BaTiO}_{3}$ & Hu et al. 1986 & $270 \mathrm{~nm}$ & 37.5 & $92 \mathrm{~nm}$ \\
\hline $\mathrm{BaTiO}_{3}$ & Hu et al. 1986 & $270 \mathrm{~nm}$ & 43.5 & $107 \mathrm{~nm}$ \\
\hline${ }^{*} \mathrm{KSCN}$ & Schranz (pers. comm) & $85 \mu \mathrm{m}$ & 16.1 & $12 \mu \mathrm{m}$ \\
\hline${ }^{*} \mathrm{~Pb}_{3}\left(\mathrm{PO}_{4}\right)_{2}$ & Van Tendeloo (pers. comm) & $60 \mathrm{~nm}$ & 24.9 & $13 \mathrm{~nm}$ \\
\hline $\mathrm{Pb}_{3}\left(\mathrm{PO}_{4}\right)_{2}$ & Van Tendeloo (pers. comm) & $96 \mathrm{~nm}$ & 28.9 & $24 \mathrm{~nm}$ \\
\hline${ }^{*} \mathrm{~Pb}_{3}\left(\mathrm{PO}_{4}\right)_{2}$ & Torres et al. 1982 & $110 \mathrm{~nm}$ & 49.7 & $51 \mathrm{~nm}$ \\
\hline $\mathrm{Pb}_{3}\left(\mathrm{PO}_{4}\right)_{2}$ & Microanalysis Lab, Cambridge & $3 \mu \mathrm{m}$ & 18.0 & $3 \mu \mathrm{m}$ \\
\hline $\mathrm{Pb}_{3}\left(\mathrm{PO}_{4}\right)_{2}$ & Microanalysis Lab, Cambridge & no scale & 20.8 & 8 \\
\hline $\mathrm{Pb}_{3}\left(\mathrm{PO}_{4}\right)_{2}$ & Van Tendeloo (pers. comm) & $150 \mathrm{~nm}$ & 18.4 & $24 \mathrm{~nm}$ \\
\hline $\mathrm{Pb}_{3}\left(\mathrm{PO}_{4}\right)_{2}$ & Torres et al. 1982 & $55 \mathrm{~nm}$ & 18.6 & $8 \mathrm{~nm}$ \\
\hline $\mathrm{Pb}_{3}\left(\mathrm{PO}_{4}\right)_{2}$ & Torres et al. 1982 & $75 \mathrm{~nm}$ & 17.4 & $11 \mathrm{~nm}$ \\
\hline $\mathrm{Pb}_{3}\left(\mathrm{PO}_{4}\right)_{2}$ & Torres et al. 1982 & $84 \mathrm{~nm}$ & 15.0 & $11 \mathrm{~nm}$ \\
\hline $\mathrm{Pb}_{3}\left(\mathrm{PO}_{4}\right)_{2}$ & Torres et al. 1982 & $90 \mathrm{~nm}$ & 18.0 & $14 \mathrm{~nm}$ \\
\hline Perovskite & Hu et al. 1992 & $70 \mathrm{~nm}$ & 25.7 & $16 \mathrm{~nm}$ \\
\hline Perovskite & Hu et al. 1992 & $570 \mathrm{~nm}$ & 23.8 & $120 \mathrm{~nm}$ \\
\hline Perovskite & Hu et al. 1992 & $970 \mathrm{~nm}$ & 12.3 & $105 \mathrm{~nm}$ \\
\hline Perovskite & Wang \& Liebermann 1993 & $125 \mathrm{~nm}$ & 32.1 & $36 \mathrm{~nm}$ \\
\hline Perovskite & Wang \& Liebermann 1993 & $330 \mathrm{~nm}$ & 37.0 & $111 \mathrm{~nm}$ \\
\hline Alkali fsp. & Brown in Salje 1993b & $200 \mathrm{~nm}$ & 21.0 & $37 \mathrm{~nm}$ \\
\hline Alkali fsp. & Brown in Salje 1993b & $220 \mathrm{~nm}$ & 23.6 & $46 \mathrm{~nm}$ \\
\hline Alkali fsp. & Brown in Salje 1993b & $310 \mathrm{~nm}$ & 18.7 & $51 \mathrm{~nm}$ \\
\hline $\mathrm{YBa}_{2} \mathrm{Cu}_{3} \mathrm{O}_{7}$ & Van Tendeloo et al. (pers. comm) & $70 \mathrm{~nm}$ & 23.4 & $14 \mathrm{~nm}$ \\
\hline $\mathrm{YBa}_{2} \mathrm{Cu}_{3} \mathrm{O}_{7}$ & Putnis in Salje 1993b & $8 \mathrm{~nm}$ & 47.3 & $3 \mathrm{~nm}$ \\
\hline $\mathrm{YBa}_{2} \mathrm{Cu}_{3} \mathrm{O}_{7}$ & Putnis in Salje 1993b & $24 \mathrm{~nm}$ & 28.1 & $6 \mathrm{~nm}$ \\
\hline $\mathrm{YBa}_{2} \mathrm{Cu}_{3} \mathrm{O}_{7}$ & Putnis in Salje 1993b & $25 \mathrm{~nm}$ & 27.0 & $6 \mathrm{~nm}$ \\
\hline $\mathrm{YBa}_{2} \mathrm{Cu}_{3} \mathrm{O}_{7}$ & Putnis in Salje 1993b & $25 \mathrm{~nm}$ & 20.4 & $4 \mathrm{~nm}$ \\
\hline $\mathrm{La}_{2-x} \mathrm{Sr}_{x} \mathrm{CuO}_{4}$ & Chen et al. 1991 & $90 \mathrm{~nm}$ & 20.8 & $16 \mathrm{~nm}$ \\
\hline $\mathrm{MnAl}$ & Van Tendeloo (pers. comm) & $50 \mathrm{~nm}$ & 27.0 & $12 \mathrm{~nm}$ \\
\hline $\mathrm{MnAl}$ & Van Tendeloo (pers. comm) & $70 \mathrm{~nm}$ & 31.9 & $12 \mathrm{~nm}$ \\
\hline $\mathrm{MnAl}$ & Van Tendeloo (pers. comm) & $70 \mathrm{~nm}$ & 19.5 & $12 \mathrm{~nm}$ \\
\hline Alkali fsp. & Hayward et al. 1996 & $120 \mathrm{~nm}$ & 16.1 & $17 \mathrm{~nm}$ \\
\hline Alkali fsp. & Hayward et al. 1996 & $120 \mathrm{~nm}$ & 17.1 & $18 \mathrm{~nm}$ \\
\hline Alkali fsp. & Hayward et al. 1996 & $140 \mathrm{~nm}$ & 16.3 & $20 \mathrm{~nm}$ \\
\hline Alkali fsp. & Hayward et al. 1996 & $160 \mathrm{~nm}$ & 7.1 & $10 \mathrm{~nm}$ \\
\hline
\end{tabular}

Note: Fitting parameters are $\lambda$ and $y_{\max }$. Angle at needle tip calculated from these.

* Illustrated in Figures 7 and 8.

crostructures (Khachaturian 1983). In contrast to exsolution lenses, only weak lattice pinning acts as a restoring force against the surface tension that leads to a collapse of the twin fragments. For continuous phase transitions (and weakly first-order transitions) narrow twins will not form during the phase transition if the effective wall width at the transition point is comparable with the thickness of a twin. Strictly speaking, the wall width, $w$, diverges in a second order or tricritical phase transition although additional strain interaction and finite size effects always maintains $w$ to the finite, but large compared to interatomic units. Typical values of $w$ observed experimentally at $T \lesssim T_{\text {c }}$ are 10-12 nm (Hayward et al. 1996). This length coincides with the observed minimum distance between pairs of parallel twin walls.

We finally comment on the experimental values of the tip angle. Theoretical predictions relate the tip angle only to the anisotropy energy (which tends to constrain the orientation of the wall close to the soft direction) but not to the bending energy. The bending energy increases with increasing curvature of the wall, its minimization always leads to locally flat twin walls - thus eliminating the needle tip altogether. A typical example for systems with dominant bending energies are anti-phase boundaries (APBs) which meander smoothly without the formation of tip structures unless they couple locally with the elastic strain (Fig. 7.19 in Salje 1993b). Dominant anisotropy energies were then predicted to lead to linear trajectories of the needle tip and smaller tip angles than in the case of curved trajectories. Our experimental observations confirm this idea. The tip angles of linear trajectories range typically from $1.6^{\circ}$ to $12^{\circ}$ whereas bent trajectories show angles between $5^{\circ}$ and $50^{\circ}$. The large variation of tip angles is partly due to the fact that we compare values of different materials and partly due to large variations of pinning effects in one and the same sample (Table 4).

Less variation occurs in forked needles (Table 5) with typical tip angles between $7^{\circ}$ and $11^{\circ}$. These values can be rationalized as follows. Consider the retraction of the inner needle while the two outer needle tips of the fork serve as pinning centers. The relevant energies are then the wall energy, which we approximate as the wall energy of the undisturbed wall

$$
\bar{E}_{\text {wall }}=\Delta g \cdot w \cdot l=\Delta g w \frac{d}{\alpha / 2}
$$

where $\Delta g$ is the excess Gibbs energy density, $w$ is the wall thickness, and $l$ is the length of the wall segment of the inner needle, $\alpha$ is the tip angle and $d$ is the distance between the two pinning centers. The anisotropy energy density is given in Equation 6, which for small angles is 


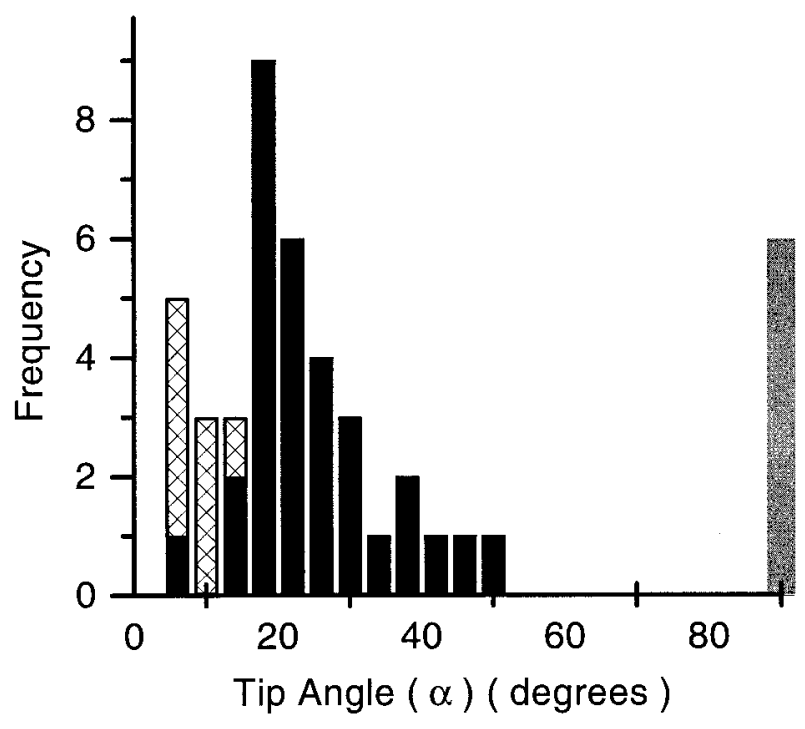

Figure 9. Variation of needle tip angles. Cross hatched $=$ straight and parabolic tips; Black = exponential tips; Light gray $=$ right-angle domain walls.

$$
E_{\text {anisotropy }}=\mathrm{U}\left(\frac{\alpha}{2}\right)^{2} .
$$

The coefficient $U$ is in the elastic limit approximated by $1 / 2 C e_{\mathrm{sp}}^{2}$, where $C$ is the elastic constant of the secondary strain and $e_{\mathrm{sp}}$ is the spontaneous strain.

The relevant energy is then

$$
\bar{E}_{\text {anisotropy }}=\frac{1}{2} C e_{\mathrm{sp}}^{2} \frac{\alpha}{2} d L
$$

where $L$ is the characteristic length over which the secondary strain propagates (e.g., the sample dimension or the distance to a compensation lattice imperfection). Minimization of the sum of both energies with respect to the tip angle leads to

$$
\left(\frac{\alpha}{2}\right)^{2}=2 \frac{\Delta g w}{C e_{\mathrm{sp}}^{2} L} .
$$

In ferroelastic materials, the elastic energy is typically on the same order of magnitude as the excess Gibbs free energy so that $\alpha^{2}$ is mainly determined by the ratio $w / L$. In the forked needle, $L$ is of the order of $d$. For $\mathrm{BaTiO}_{3}$, we can estimate $w=2 \mathrm{~nm}$ and $L=270 \mathrm{~nm}$, which leads to a tip angle of $10^{\circ}$. Similar values are found for other materials. Their order of magnitude agrees well with the observed angles, bearing in mind the crude nature of the estimate.

We may now use this approach to discuss some predictions for the temperature dependence of the tip angle for a structural phase transition. The temperature evolution of the wall energy $\Delta g w \propto\left|T-T_{\mathrm{c}}\right|^{3 / 2}$ in a secondorder phase transition (e.g., Salje 1993b) is not necessarily identical to the temperature dependence of the anisotropy energy $1 / 2 C e_{\mathrm{sp}}^{2} \cdot L$. In case of a constant length $L$ and temperature independent elastic constants $C$, the anisot-

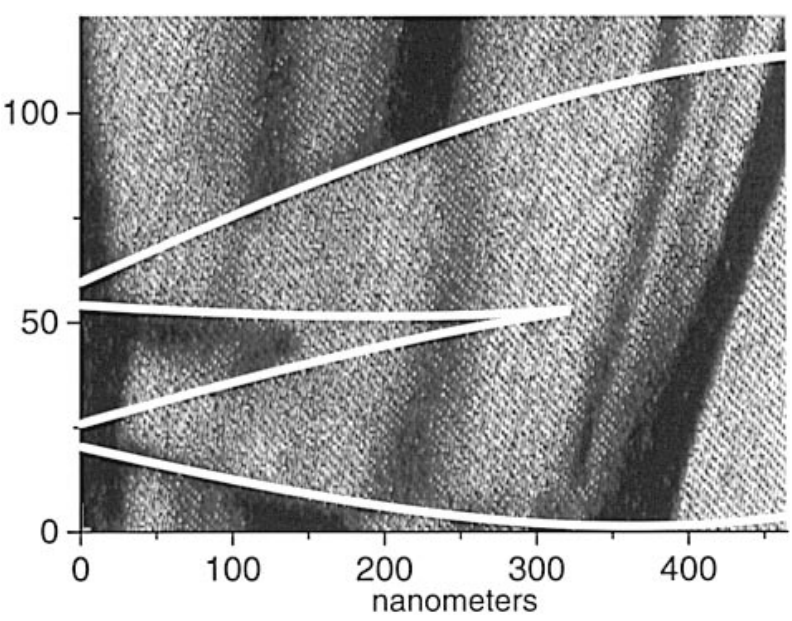

Figure 10. Needle splitting in $\mathrm{Pb}_{3}\left(\mathrm{PO}_{4}\right)_{2}$. This needle is from the same original figure as the single needle in Figure 7B. Both axes have the same units.

ropy energy scales as $\left|T-T_{\mathrm{c}}\right|$ for a second-order transition and as $\left|T-T_{\mathrm{c}}\right|^{1 / 2}$ in a tricritical phase transition. In both cases, the tip angle $\alpha$ depends on temperature as $\left|T-T_{\mathrm{c}}\right|^{1 / 4}$, i.e., $\alpha$ decreases when temperature approaches $T_{\mathrm{c}}$. The physical reason is that the wall energy decreases more rapidly than the anisotropy energy for $T \rightarrow T_{\mathrm{c}}$.

The situation is reversed if in improper ferroelastic materials the wall energy is dominated by the elastic energy and not by the thermodynamic order parameter. The temperature dependence of $\Delta g$ and $1 / 2 C e_{\mathrm{sp}}^{2}$ are then approximately the same and cancel each other in Equation 17. The temperature dependence of $\alpha$ is then determined by $W^{1 / 2} \propto\left|T-T_{\mathrm{c}}\right|^{1 / 4}$ which leads to an increase of $\alpha$ for $T \rightarrow$ $T_{\mathrm{c}}$. This estimate implies that forked needles and zigzag walls may change the tip angles whereas isolated needle domains do not because of the dominant pinning effects.

Trajectories of twin walls of needle twins show the same geometrical pattern as predicted from the interplay of anisotropy energies, bending energies, and pinning energies. It is expected that an important annealing mechanism for the twin structure of minerals is the formation and retraction of such needle domains.

The difficulties in using twin structures for the assessment of geological processes were already illuminated for feldspars by Smith (1974b). Not all of these difficulties have been overcome but the fundamental understanding of twins and, much more importantly, of walls between twins has been advanced dramatically. First, the focus is much more on transformation twins than growth twins (Salje 1985). Second, the concepts of thick twin walls, wetting and "internal structures" of walls are firmly established. These phenomena have not yet been exploited for geological applications. This paper has endeavored to emphasize another aspect of transformation twins, namely their hierarchical structures with the basic element of twin walls and higher order configurations of corner domains, needles, combs of needles, zigzag bands of needles, 
TABLE 5. Materials in which needle splitting is observed

\begin{tabular}{|c|c|c|c|c|c|}
\hline Material & Reference & $y_{\max }$ & Tip-angles & $\lambda$ & $\begin{array}{c}\text { Relative } \\
\text { anisotropy energy }\end{array}$ \\
\hline $\mathrm{GdBa}_{2} \mathrm{Cu}_{3} \mathrm{O}_{7}$ & Shmytko et al. 1989 & & & & \\
\hline Single needle $(\alpha)$ & & 1.7 & 10.3 & 19 & \\
\hline Split pair inner $(\beta)$ & & 1.5 & 4.6 & 18.2 & \\
\hline Split pair outer $(\gamma)$ & & 1.9 & 4.6 & 23.2 & \\
\hline Complete split pair (a) & & & 9.2 & & 0.26 \\
\hline $\begin{array}{l}\text { Single needle of same width } \\
\text { and tip angle as pair (b) }\end{array}$ & & & & & 0.26 \\
\hline $\begin{array}{l}\text { Single needle of same width } \\
\text { and tip length as pair (c) }\end{array}$ & & & & & 0.46 \\
\hline $\mathrm{YBa}_{2} \mathrm{Cu}_{3} \mathrm{O}_{7}$ & Van Tendeloo et al. 1990 & & & & \\
\hline Single needle $(\alpha)$ & & $14 \mathrm{~nm}$ & 23.4 & $70 \mathrm{~nm}$ & \\
\hline Split pair inner $(\beta)$ & & $24 \mathrm{~nm}$ & 3.5 & $401 \mathrm{~nm}$ & \\
\hline Split pair outer $(\gamma)$ & & $31 \mathrm{~nm}$ & 3.8 & $468 \mathrm{~nm}$ & \\
\hline Complete split pair (a) & & & 7.3 & & 3.5 \\
\hline $\begin{array}{l}\text { Single needle of same width } \\
\text { and tip angle as pair (b) }\end{array}$ & & & & & 3.6 \\
\hline $\begin{array}{l}\text { Single needle of same width } \\
\text { and tip length as pair (c) }\end{array}$ & & & & & 6.8 \\
\hline${ }^{*} \mathrm{~Pb}_{3}\left(\mathrm{PO}_{4}\right)_{2}$ & Torres et al. 1982 & & & & \\
\hline Single needle $(\alpha)$ & & $51 \mathrm{~nm}$ & 49.7 & $110 \mathrm{~nm}$ & \\
\hline Split pair inner $(\beta)$ & & $16 \mathrm{~nm}$ & 3.5 & $261 \mathrm{~nm}$ & \\
\hline Split pair outer $(\gamma)$ & & $39 \mathrm{~nm}$ & 6.9 & $322 \mathrm{~nm}$ & \\
\hline Complete split pair (a) & & & 10.4 & & 5.7 \\
\hline $\begin{array}{l}\text { Single needle of same width } \\
\text { and tip angle as pair (b) }\end{array}$ & & & & & 6.7 \\
\hline $\begin{array}{l}\text { Single needle of same width } \\
\text { and tip length as pair (c) }\end{array}$ & & & & & 9.4 \\
\hline $\mathrm{BaTiO}_{3}$ & Hu et al. 1986 & & & & \\
\hline Single needle $(\alpha)$ & & $107 \mathrm{~nm}$ & 43.5 & $270 \mathrm{~nm}$ & \\
\hline Split pair inner $(\beta)$ & & $32 \mathrm{~nm}$ & 4.0 & $459 \mathrm{~nm}$ & \\
\hline Split pair outer $(\gamma)$ & & $78 \mathrm{~nm}$ & 7.2 & $618 \mathrm{~nm}$ & \\
\hline Complete split pair (a) & & & 11.2 & & 12.1 \\
\hline $\begin{array}{l}\text { Single needle of same width } \\
\text { and tip angle as pair (b) }\end{array}$ & & & & & 13.9 \\
\hline $\begin{array}{l}\text { Single needle of same width } \\
\text { and tip length as pair (c) }\end{array}$ & & & & & 19.7 \\
\hline
\end{tabular}

tweed, etc. To relate twinning to geological events, each of these features must be looked at separately. For instance, the appearance of individual twin walls or parallel arrays of twin walls has probably not much meaning for the analysis of the cooling history of a mineral (unless the wall distance is on a very fine scale) Such mesoscopic structures are commonly related to external stresses rather than the time of cooling. Corner domains, on the other hand, represent high energy contributions and are expected to disappear quickly under appropriate annealing conditions. Their appearance may indicate very quick quench processes. Similarly, incomplete needle formation (Fig. 1b and 1c) is also a sign of rapid quench. Needles retract in time so that long, pointed needles are signs of early stages of coarsening whereas short, sturdy needles which contain only the bend walls are more expected for late stages. Even longer annealing is probably needed to eliminate these short needles when they form combs. Any comb or zigzag pattern can form a straight wall (e.g., a comb of pericline walls in triclinic hypersolvus alkali feldspar can form an albite wall and vice versa) but the energy barrier is determined by the anisotropy energy. This energy is usually much higher than the depinning energy. The slowest movement is the sideways motion of walls, e.g., leaving the grain or to locally coalesce with a second wall to form another needle. This movement can, however, vastly accelerate if external stress is applied. It might well be that such needle formation inside parallel stripe patterns are sensitive to stresses on a mineral but insensitive to kinetic annealing under stress-free conditions. After much of such intrinsic properties of twins are understood, the application to minerals in the geological context is clearly the next step in the quest of quantitative measures for geological processes.

\section{REFERENCES CITED}

Bismayer, U. and Salje, E.K.H. (1981) Ferroelastic phases in $\mathrm{Pb}_{3}\left(\mathrm{PO}_{4}\right)_{2}$ $\mathrm{Pb}_{3}\left(\mathrm{AsO}_{4}\right)_{2} \mathrm{X}$-ray and optical experiments. Acta Crystallographica, A37, 145.

Burger, M.J. (1945) The genesis of twin crystals. American Mineralogist, 30, 369-482.

Carpenter, M.A. (1994) Evolution and properties of antiphase boundaries in silicate minerals. Phase Transitions, 48, 189-199.

Chrosch, J. and Salje, E.K.H. (1994) Thin domain walls in $\mathrm{YBa}_{2} \mathrm{Cu}_{3} \mathrm{O}_{7-\delta}$ and their rocking curves: An X-ray study. Physica, C, 225, 111-116.

Chen, C.H., Cheong, S-W., Werder, D.J., Cooper, A.S., and Rupp, L.W. (1991) Low temperature microstructure and phase transition in $\mathrm{La}_{2-x} \mathrm{Sr}_{x} \mathrm{CuO}_{4}$ and $\mathrm{La}_{2-x} \mathrm{Ba}_{x} \mathrm{CuO}_{4}$. Physica C, 175, 301-309. 
Dobrikov, A.A. and Presnyakova, O.V. (1980) Investigation of crystal lattice defects of $\mathrm{PbZrO}_{3}$ single crystals by transmission electron microscopy. Kristall and Technik, 15, 1317-1321.

Gordon, W.A., Peacor, D.R., Brown, P.E., Essene, E.J., and Allard, L.F. (1981) Exsolution relationship in a clinopyroxene of average composition $\mathrm{Ca}_{0.43} \mathrm{Mn}_{0.69} \mathrm{Mg}_{0.82} \mathrm{Si}_{2} \mathrm{O}_{6}$ : X-ray diffraction and analytical electron microscopy. American Mineralogist, 66, 127-141.

Hayward, S.A. and Salje, E.K.H. (1996) Displacive phase transition in anorthoclase: The "plateau effect" and the effect of T1-T2 ordering on the transition temperature. American Mineralogist, 81, 1332-1336.

Hayward, S.A., Chrosch, J., Salje, E.K.H., and Carpenter, M.A. (1996) Thickness of pericline twin walls in anorthoclase: an X-ray diffraction study. European Journal of Mineralogy, 8, 1310-1310.

Heaney, P.J. and Veblen, D.R. (1990) A high-temperature study of the low-high leucite phase transition using the transmission electron microscope. American Mineralogist, 75, 464-476.

Heuer, A.H., Nord, G.L., Lally, J.S., and Christie, J.M. (1976) Origin of the c domains in anorthite. In H.R. Wenk, Ed., Application of electron microscopy in mineralogy, p. 345-353. Springer-Verlag, Berlin.

Hu,Y., Chan, H.M., Wen, Z.X., and Harmer, M.P. (1986) Scanning electron microscopy and transmission electron microscopy study of ferroelectric domains in doped $\mathrm{BaTiO}_{3}$. Journal of the American Ceramic Society, 69, 594-602.

Hu, M., Wenk, H-R., and Sinitsyna, D. (1992) Microstructures in natural perovskites. American Mineralogist, 77, 359-373.

Houchmanzadeh, B., Lajzerowicz, J., and Salje, E.K.H. (1991) Order parameter coupling and chirality of domain walls. Journal of Physics and Condensed Matter, 3, 5163-5169.

Khachaturian, A.G. (1983) Theory of structural transformations in solids, 574 p. Wiley, New York.

Mazzi, F., Galli, E., and Gottardi, G. (1976) The crystal structure of tetragonal leucite. American Mineralogist, 61, 108-115.

McLaren, A.C. (1984) Transmission electron microscope investigation of the microstructures in microclines. In W.L. Brown, Ed., Feldspars and feldspathoids, p. 373-409. Reidel, Dordrecht.

Müller, W.F. and Schreyer, W. (1991) Microstructural variations in a natural cordierite from the Eifel volcanic field, Germany, European Journal of Mineralogy, 3, 915-931.

Müller, W.F. and Wenk, H.R. (1973) Changes in the domain structure of anorthite induced by heating. Neues Jahrbuch für Mineralogie Monatshefte, 17-26.

Palmer, D.C., Putnis, A., and Salje, E. (1988) Twinning in tetragonal leucite. Physics and Chemistry of Minerals, 16, 298-303.

Peacor, D.R. (1968) A high-temperature single crystal diffractometer study of leucite, $(\mathrm{K}, \mathrm{Na}) \mathrm{AlSi}_{2} \mathrm{O}_{6}$. Zeitschrift für Kristallographie, 127, 213224.

Putnis, A. and Salje, E.K.H. (1994) Tweed microstructures: experimental observations and some theoretical models. Phase Transitions, 85-105.

Sadanaga, R. and Ozawa, T. (1968) Thermal transition of leucite. Mineralogical Journal, 5, 321-333.

Salje, E.K.H. (1985) Thermodynamics of sodium feldspar I: order parameter treatment and strain induced coupling effects. Physics and Chemistry of Minerals, 12, 93-98.

(1993a) On the kinetics of partially conserved order parameters: A possible mechanism for pattern formation. Journal of Physics: Condensed Matter, 5, 4775-4784.

(1993b) Phase transitions in ferroelastic and co-elastic crystals, (student edition), 229 p. Cambridge University Press, Cambridge, England.

Salje, E.K.H. and Ishibashi, Y. (1996) Mesoscopic structures in ferroelastic crystals: needle twins and right-angled domains. Journal of Physics: Condensed Matter, 8, 1-19.

Salje, E.K.H., Kuscholke, B., Wruck, B., and Kroll, H. (1985) Thermodynamics of sodium feldspar II: experimental results and numerical calculations. Physics and Chemistry of Minerals, 12, 99-107.

Salje, E.K.H., Wruck, B., Graeme-Barber, A., and Carpenter, M.A. (1993) Experimental test of rate equations: Time evolution of $\mathrm{Al}, \mathrm{Si}$ ordering in anorthite $\mathrm{CaA}_{2} \mathrm{Si}_{2} \mathrm{O}_{8}$. Journal of Physics: Condensed Matter, 5, 2961-2968.

Shmytko, I.M., Shekhtman, V.S., Ossipyan, A., and Afonikova, N.S. (1989) Twin structures and structure of twin boundaries in 1-2-3- $\mathrm{O}_{7-5}$ crystals. Ferroelectrics, 97, 151-170.

Smith, J.V. (1974a) Feldspar minerals, vol. 1, Crystal structures and physical properties, 622 p. Springer Verlag, Berlin.

(1974b) Feldspar minerals, vol. 2, Chemical and textural properties, 690 p. Springer Verlag, Berlin.

Smith, J.V. and Brown, W.L. (1988) Feldspar minerals, vol. 1, Crystal structures, physical, chemical and microtextural properties (2nd edition), 828 p. Springer-Verlag, Berlin.

Smith, J.K., McLaren, A.C., and O'Donell, R.G. (1987) Optical and electron microscope investigation of temperature-dependent microstructures in anorthoclase. Canadian Journal of Earth Sciences, 24, 528-543.

Tsatskis, I. and Salje, E.K.H. (1996) Time evolution of pericline twin domains in alkali feldspars: A computer-simulation study. American Mineralogist, 81, 800-810.

Tsatskis, I., Salje, E.K.H., and Heine, V. (1994) Pattern formation during phase transitions: kinetics of partially conserved order parameters and the role of gradient energies. Journal of Physics: Condensed Matter, 6, $11027-11034$.

Torres, J., Roucau, C., and Ayroles, R. (1982) Investigation of the interactions between ferroelastic domain walls and of the structural transition in lead phosphate observed by electron microscopy. Physica Status Solidi, A 70, 659-69.

Van Tendeloo, G., Van Landuyt, J., and Amelinckx, S. (1976) The $\alpha-\beta$ transition in quartz and $\mathrm{AlPO}_{4}$ as studied by electron microscopy and diffraction, Physica Status Solidi, A33, 723-735.

Van Tendeloo, G., Broddin, D., Zandbergen, H.W., and Amelinckx, S (1990) Detwinning mechanisms, twinning dislocations and planar defects in $\mathrm{YBa}_{2} \mathrm{Cu}_{3} \mathrm{O}_{7-\delta}$. Physica, C, 167, 627-639.

Wang,Y. and Liebermann, R.C. (1993) Electron microscopy study of domain structure due to phase transitions in natural perovskites. Physics and Chemistry of Minerals, 20, 147-158.

Wruck, B., Salje, E., and Graeme-Barber, A. (1991) Kinetic rate laws derived from order parameter theory IV: Kinetics of Al-Si disordering in Na-feldspars. Physics and Chemistry of Minerals, 17, 700-710.

Wyart, J. (1938) Étude sur la leucite. Bulletin de la Société Francaise de Mineralogie, 61, 228-238.

$\mathrm{Xu}, \mathrm{H}$. and Heaney, P.J. (1997) Memory effects of domain structures during displacive phase transitions: A High-temperature TEM study of quartz and anorthite. American Mineralogist, 82, 99-108.

Xu, H., Buseck, P.R., and Carpenter, M.A. (1997) Twinning in synthetic anorthite: A transmission electron microscopy investigation. American Mineralogist, 82, 125-130.

Yamamoto, N., Yagi, K., and Tafto, J. (1977) Electron microscopic studies of ferroelectric and ferroelastic $\mathrm{Gd}_{2}\left(\mathrm{MoO}_{4}\right)_{3}$. I: Interactions between ferroelectric domains walls. Physica Status Solidi, A42, 257-265.

Zhu, Y., Suenaga, M., and Tafto, J. (1993) The interface of orthogonally oriented twins in $\mathrm{YBa}_{2} \mathrm{Cu}_{3} \mathrm{O}_{7}$. Philosophical Magazine, A67, 10571069.

ManusCript ReCEIVEd June 23, 1997

ManusCRipt aCCePted March 4, 1998

PAPER handled By Gordon L. NoRd JR. 